\section{Analysis of a poultry slaughter process: Influence of process stages on the microbiological contamination of broiler carcasses}

\author{
Denise Althaus, Claudio Zweifel, \\ Roger Stephan
}

Institute for Food Safety and Hygiene, Vetsuisse Faculty, University of Zurich, Switzerland

\begin{abstract}
In a large-scale Swiss poultry abattoir, a microbiological process analysis of broiler carcasses was performed. At each selected process stage (scalding, plucking, evisceration, washing, and chilling), 90 carcasses from 30 flocks were sampled and examined for Campylobacter, Salmonella, Escherichia coli, Enterobacteriaceae, and extended-spectrum $\beta$-lactamases-producing Enterobacteriaceae. With regard to Campylobacter counts on carcasses, plucking tended to slightly increase the results (on average by $0.4 \log \mathrm{CFU} / \mathrm{g}$ ), whereas mean counts from plucked and chilled carcasses were comparable (3.1 log CFU/g after plucking, $3.0 \mathrm{log}$ CFU/g in the chiller). The Campylobacter results of chilled carcasses are thereby likely to comply with the newly defined requirements of the European Union (process hygiene criterion for Campylobacter). With regard to Escherichia coli and Enterobacteriaceae counts on carcasses, plucking clearly reduced the results (on average by 0.8 and $0.9 \log \mathrm{CFU} / \mathrm{g}$ ), whereas mean counts from plucked and chilled carcasses were comparable (3.4 and $3.5 \log \mathrm{CFU} / \mathrm{g}$ after plucking, $3.4 \log \mathrm{CFU} / \mathrm{g}$ in the chiller). In contrast, Salmonella spp. were not detected on broiler carcasses and extended-spectrum $\beta$-lactamases-producing Enterobacteriaceae only rarely $(1.8 \%)$. Such abattoir-specific data are of central importance for assessment of slaughter process performance and if necessary for the implementation of effective measures in the slaughter process.
\end{abstract}

\section{Introduction}

The slaughter of poultry in large-scale slaughterhouses is a rapid and highly automated process. Despite technological advancements, there are still considerable opportunities for contamination and spread of bacteria during slaughter. To ensure food safety, strict adherence to good practices of slaughter hygiene, along with risk-based preventive measures (HACCP approach), is of central importance. For assessment of slaughter process performance, a process analysis including the identification of operations increasing or decreasing the microbiological contamination of carcasses is required (Brown et al., 2000; Milios et al., 2014; Zweifel et al., 2014).

With regard to slaughtered broilers, such examinations will soon include also Campylobacter, which is the leading cause of acute bacterial gastroenteritis in humans (EFSA/ECDC, 2016). Handling and consumption of poultry are thereby considered major sources for human illnesses (Boysen et al., 2014; EFSA, 2010a). Various risk assessments indicate that reductions of Campylobacter counts on carcasses might cause a significant reduction in associated human cases (EFSA, 2011; Nauta et al., 2009; Rosenquist et al., 2003). Moreover, certain poultry slaughterhouses are more successful than others in containing the Campylobacter contamination of carcasses (EFSA, 2010b; Habib et al., 2012a).

With the required monitoring of Salmonella and the planned introduction of Campylobacter as process hygiene criteria for slaughtered broilers in the European Union (EU), microbiological data are also required for the implementation of adequate measures in the slaughter process. The present study was performed in a large-scale poultry abattoir and the aim was to investigate the effects of selected slaughter operations on the microbiological contamination of broiler carcasses (selected foodborne pathogens and indicator bacteria).

\section{Materials and Methods}

\section{Abattoir and slaughter process}

This study was based on investigations carried out during May to June 2017 in a large-scale Swiss poultry abattoir. Most processing steps were automated. First, broilers were stunned using $\mathrm{CO}_{2}$, manually shackled, and exsanguinated. Broilers were then scalded (immersion) and plucked. Scalding comprised two scalding tanks (tank 1: on average $52.4^{\circ} \mathrm{C}, 120 \mathrm{~s}$; tank 2: on average $52.5^{\circ} \mathrm{C}, 75 \mathrm{~s}$ ) and plucking consisted of two segments. After transfer to the evisceration line, intestines were drawn out of the body's cavity (vent cutter, opener, eviscerator), the neck was removed, and washing steps with cold potable water removed visible dirt. Finally, carcasses were chilled.
Correspondence: Roger Stephan, Institute for Food Safety and Hygiene, Vetsuisse Faculty University of Zurich Winterthurerstrasse 272, 8057 Zurich, Switzerland.

Tel.: +41 44635 8651, Fax: +41 446358908 . E-mail: roger.stephan@uzh.ch

Key words: Broiler carcasses; Slaughter process; Campylobacter; Escherichia coli, Enterobacteriaceae.

Acknowledgments: the authors thank the staff of the slaughterhouse involved in this study for collection of samples and general assistance.

Contributions: the authors contributed equally.

Conflict of interest: the authors declare no potential conflict of interest.

Received for publication: 24 September 2017. Revision received: 29 October 2017.

Accepted for publication: 29 October 2017.

This work is licensed under a Creative Commons Attribution-NonCommercial 4.0 International License (CC BY-NC 4.0).

(C) Copyright D. Althaus et al., 2017

Licensee PAGEPress, Italy

Italian Journal of Food Safety 2017; 6:7097

doi:10.4081/ijfs.2017.7097

\section{Sampling}

Broiler carcasses were sampled at five slaughter process stages: after scalding, after plucking, after evisceration, after washing, and in the chiller. At each stage, 90 carcasses from 30 flocks were sampled during 10 sampling days. Each carcass sample consisted of pooled neck and breast skin. In addition, 30 scalding water samples (15 per scalding tank) were collected during five sampling days.

\section{Microbiological examinations}

Samples were analyzed qualitatively for Salmonella spp. and quantitatively for Campylobacter spp., Escherichia (E.) coli, Enterobacteriaceae, and extended-spectrum $\beta$-lactamases (ESBL)-producing Enterobacteriaceae. The qualitative examination for Salmonella spp. was done in accordance with ISO 6579:2007-10 with a modification. Briefly, a subset of each carcass sample (10 g) or of each scalding water sample $(10 \mathrm{~mL})$ was enriched $\left(24 \mathrm{~h}, 37^{\circ} \mathrm{C}\right)$ at a 1:10 ratio in buffered peptone water (Oxoid, Pratteln, $\mathrm{CH}$ ). From the first enrichment, $0.1 \mathrm{~mL}$ were incubated $\left(24 \mathrm{~h}, 41.5^{\circ} \mathrm{C}\right)$ in $10 \mathrm{~mL}$ of Rappaport-Vassiliadis broth (Oxoid). The enriched samples were subcultured $\left(24 \mathrm{~h}, 37^{\circ} \mathrm{C}\right)$ on xylose-lysine-desoxycholate (XLD) agar (Bio-Rad, Reinach, 
$\mathrm{CH}$ ) and mannitol lysine crystal violet brilliant green (MLCB) agar (Oxoid). For the quantitative examinations, a subset of each carcass sample (10 g) was homogenized at a $1: 10$ ratio in $0.85 \%$ saline solution and analyzed using a spiral plater (Eddy Jet, IUL, Barcelona, E). Scalding water samples were quantitatively analyzed by spreading 0.1 $\mathrm{mL}$. The following agars and conditions were used for the quantitative examinations: CampyFood agar (bioMérieux, Geneva, CH; 48 h, $41.5^{\circ} \mathrm{C}$, microaerophilic conditions), Rapid E. coli $2^{\mathrm{TM}}$ agar (BioRad; $24 \mathrm{~h}, 37^{\circ} \mathrm{C}$ ), violet red bile glucose (VRBG) agar (Becton Dickinson, Allschwil, $\mathrm{CH} ; 48 \mathrm{~h}, 30^{\circ} \mathrm{C}$, anaerobic conditions), and chromogenic Brilliance ESBL agar (Oxoid; $24 \mathrm{~h}, 37^{\circ} \mathrm{C}$ ).

\section{Data analysis}

Colony counts of quantitatively analyzed samples were expressed as log CFU/g or $\log \mathrm{CFU} / \mathrm{mL}$. The detection limit was $200 \mathrm{CFU} / \mathrm{g}(2.3 \mathrm{log} \mathrm{CFU} / \mathrm{g}$ ) for carcass samples and $10 \mathrm{CFU} / \mathrm{mL}(1.0 \log \mathrm{CFU} / \mathrm{mL})$ for scalding water samples. Quantitative analysis was based on counts above the detection limit and results were compared by reference to mean $\log$ values. Mean $\log$ values differing by $<0.5 \log$ units were regarded as similar for practical purposes. Statistical analysis was performed using JMP 13.0 (SAS Institute, Cary, NC, USA). The level of significance was set at $\alpha=0.05$. Analysis of variance (ANOVA) and Tukey HSD test were used to analyze differences in counts between sequential process stages and scalding segments.

\section{Results and Discussion}

\section{Microbiological slaughter process analysis: Salmonella spp. and Campylobacter spp.}

While Salmonella spp. were not detected (after enrichment) in any of the 450 samples from broiler carcasses, 131 (29\%) of all carcasses showed Campylobacter counts above the detection limit. At the different process stages, the proportion Campylobacter-positive carcasses ranged from 11 to $42 \%$ (Table 1). Because consumer risks seem mainly associated with highly contaminated products, the distribution of Campylobacter counts at different ranges is of importance. The distribution of counts at different ranges is shown in Table 1. Over all process stages, $50 \%$ of the Campylobacter-positive carcasses showed counts $<3.0 \log \mathrm{CFU} / \mathrm{g}$ and $42 \%$ between 3.0 and $4.0 \log \mathrm{CFU} / \mathrm{g}$. After scalding, Campylobacter counts averaged out at 2.7 $\log \mathrm{CFU} / \mathrm{g}$ (Table 1, Figure 1). Plucking tended to increase and washing to reduce the counts (on average by $0.4 \log \mathrm{CFU} / \mathrm{g}$ ), whereas results remained mainly constant by evisceration and chilling. The resulting mean count of chilled carcasses was $3.0 \mathrm{log}$ $\mathrm{CFU} / \mathrm{g}$. With regard to Campylobacter and poultry slaughter, the available literature often showed common trends: reductions by scalding, rather increases by plucking, no changes or increases by evisceration, and reductions by washing and chilling (Berghaus et al., 2013; Duffy et al., 2014; Guerin et al., 2010; Huang et al., 2017;
Pacholewicz et al., 2015b; Rosenquist et al., 2006; Seliwiorstow et al., 2015). However, direct comparisons are often hampered because the effect of a certain process stage on Campylobacter strongly depends on the respective conditions (e.g. temperature and time conditions used for scalding, varying washing steps, differing chilling methods).

Furthermore, microbiological criteria for Campylobacter spp. on slaughtered broilers have been recently investigated (Comin et al., 2014; EFSA, 2011; Lee et al., 2015; Nauta et al., 2012). With a new amendment of Reg. (EC) No. 2073/2005 (EC, 2005), the EU plans to implement a quantitative process hygiene criterion for Campylobacter on broiler carcasses after chilling. The amendment lays down requirements in view of sampling, sampling plans, sample processing, microbiological examinations, evaluation of results, and corrective actions (Table 2). Campylobacter results are thereby rated as satisfactory if not more than $20(40 \%)$ of 50 samples (one sample consists of three neck skin samples from one flock) from 10 consecutive samplings show counts $>1000 \mathrm{CFU} / \mathrm{g}(\mathrm{n}=50$, $\mathrm{c}=20$ ). Thereby, it must be considered that i) countries with more favorable Campylobacter contamination levels may apply stricter c values and ii) c values will be reduced $2020(\mathrm{c}=15)$ and $2025(\mathrm{c}=10)$. Although the design of the present study does not fully correspond with the EU requirements, the results of the chilled carcasses were evaluated on the basis of the defined EU limits. Of the 90 chilled broiler carcasses (Table 1), only $12(13 \%)$ showed

Table 1. Campylobacter, Escherichia coli, and Enterobacteriaceae results from broiler carcasses at selected stages of slaughter (n=90 at each process stage, sampling comprised 10 sampling days and a total of 30 broiler flocks).

\begin{tabular}{|c|c|c|c|c|c|c|c|c|c|}
\hline \multirow[t]{2}{*}{ Microorganisms } & \multirow[t]{2}{*}{ Process stage } & \multicolumn{2}{|c|}{$\begin{array}{c}\text { Results } \geq \text { detection } \\
\text { limit }\end{array}$} & \multicolumn{2}{|c|}{ Counts $^{\mathrm{a}}$} & \multicolumn{4}{|c|}{$\begin{array}{l}\text { Number (\%) of carcasses with counts } \\
\geq \text { detection limit at different ranges } \\
(\log \mathrm{CFU} / \mathrm{g})^{\mathrm{b}}\end{array}$} \\
\hline & & Carcasses, \% & Flocks, \% & $x$ & SD & $<3.0$ & $3.0-4.0$ & $4.0-5.0$ & $>5.0$ \\
\hline \multirow[t]{5}{*}{ Campylobacter } & After scalding & 11.1 & 26.7 & 2.69 & 0.39 & $8(80.0)$ & $2(20.0)$ & $0(0.0)$ & $0(0.0)$ \\
\hline & After plucking & 42.2 & 53.3 & 3.13 & 0.63 & $17(44.7)$ & $18(47.4)$ & $3(7.9)$ & $0(0.0)$ \\
\hline & After evisceration & 41.1 & 50.0 & 3.20 & 0.68 & $14(37.8)$ & $17(45.9)$ & $6(16.2)$ & $0(0.0)$ \\
\hline & After washing & 23.3 & 40.0 & 2.77 & 0.45 & $13(61.9)$ & $8(38.1)$ & $0(0.0)$ & $0(0.0)$ \\
\hline & In the chiller & 27.8 & 36.7 & 2.99 & 0.60 & $13(52.0)$ & $10(40.0)$ & $2(8.0)$ & $0(0.0)$ \\
\hline \multirow[t]{5}{*}{ E. coli } & After scalding & 94.4 & 100 & 4.16 & 1.08 & $12(14.1)$ & $21(24.7)$ & $35(41.2)$ & $17(20.0)$ \\
\hline & After plucking & 92.2 & 100 & 3.37 & 0.88 & $31(37.3)$ & $33(39.8)$ & $12(14.5)$ & $7(8.4)$ \\
\hline & After evisceration & 96.7 & 100 & 3.75 & 0.73 & $11(12.6)$ & $42(48.3)$ & $28(32.2)$ & $6(6.9)$ \\
\hline & After washing & 91.1 & 100 & 3.34 & 0.74 & $29(35.4)$ & $37(45.1)$ & $14(17.1)$ & $2(2.4)$ \\
\hline & In the chiller & 82.2 & 96.7 & 3.41 & 0.75 & $22(29.7)$ & $38(51.4)$ & $12(16.2)$ & $2(2.7)$ \\
\hline \multirow[t]{5}{*}{ Enterobacteriaceae } & After scalding & 90.0 & 96.7 & 4.42 & 1.01 & $6(7.4)$ & $19(23.5)$ & $36(44.4)$ & $20(24.7)$ \\
\hline & After plucking & 93.3 & 96.7 & 3.52 & 0.86 & $22(26.2)$ & $38(45.2)$ & $18(21.4)$ & $6(7.1)$ \\
\hline & After evisceration & 97.8 & 100 & 3.83 & 0.69 & $8(9.1)$ & $43(48.9)$ & $31(35.2)$ & $6(6.8)$ \\
\hline & After washing & 94.4 & 100 & 3.34 & 0.76 & $29(34.1)$ & 38 (44.7) & $15(17.6)$ & $3(3.5)$ \\
\hline & In the chiller & 87.8 & 100 & 3.39 & 0.74 & $22(27.8)$ & $41(51.9)$ & $14(17.7)$ & $2(2.5)$ \\
\hline
\end{tabular}

${ }^{\mathrm{a}} \chi$ and SD, mean $\log \mathrm{CFU} / \mathrm{g}$ and standard deviation of results $\geq$ detection limit $(2.3 \log \mathrm{CFU} / \mathrm{g})$. ${ }^{\mathrm{b} C a m p y l o b a c t e r:} 131$ carcasses with $\geq 2.3 \log \mathrm{CFU} / \mathrm{g}$, E. coli: 411 carcasses with $\geq 2.3 \log$ CFU/g, Enterobacteriaceae: 417 carcasses with $\geq 2.3 \log \mathrm{CFU} / \mathrm{g}$. 
Campylobacter counts $\geq 1000 \mathrm{CFU} / \mathrm{g}$ and only nine $(10 \%)$ of them exceeded 1000 $\mathrm{CFU} / \mathrm{g}$. Looking at sets of consecutive 50 samples (moving window: samples 1-50, 655 , etc.), in each case only five $(10 \%)$ exceeded $1000 \mathrm{CFU} / \mathrm{g}$. Thus, the Campylobacter results of chilled carcasses likely comply with the EU limits. First experiences with a newly implemented Campylobacter performance target using to a certain degree a similar approach have recently been reported from New Zealand (Lee et al., 2015).

\section{Microbiological slaughter process analysis: Escherichia coli and Enterobacteriaceae}

E. coli and Enterobacteriaceae were used as indicator of fecal contamination on broiler carcasses. Of the 450 carcasses, $91 \%$ and $93 \%$ showed counts above the detection limit for E. coli and Enterobacteriaceae, respectively. The distribution of counts at different ranges is shown in Table 1. During the slaughter process, trends and counts were comparable for $E$. coli and Enterobacteriaceae (Figure 1). Enterobacteriaceae were therefore mainly E. coli.

After scalding, E. coli and Enterobacteriaceae counts averaged out at 4.2 and $4.4 \log$ CFU/g, respectively (Table 1, Figure 1). Plucking reduced the counts (on average by 0.8 and $0.9 \log \mathrm{CFU} / \mathrm{g}$; $\mathrm{P}<0.05$ ), probably due to physical removal. Pacholewicz et al. (2015b) recently also reported reductions by plucking, whereas an earlier study described an opposite effect (Berrang and Dickens, 2000). In the present study, evisceration slightly increased the counts (on average by 0.4 and $0.3 \quad \log$
$\mathrm{CFU} / \mathrm{g} ; \mathrm{P}<0.05$ for $E$. coli), whereas washing tended to reduce the counts (on average by 0.4 and $0.5 \log$ CFU/g; $P<0.05)$. Thus, as described previously (Berrang and Dickens, 2000; Pacholewicz et al., 2015b), evisceration operations were performed without extensive additional fecal contamination. By washing with cold water probably rather redistributions than real reductions were achieved (Loretz et al., 2010). Using air chilling with an usually limited microbial effect (James et al., 2006), results remained mainly constant and resulting mean $E$. coli and Enterobacteriaceae counts of chilled carcasses were $3.4 \log \mathrm{CFU} / \mathrm{g}$.

\section{Microbiological slaughter process analysis: extended-spectrum $\beta$-lactamases-producing \\ Enterobacteriaceae}

With regard to antibiotic resistance, ESBL-producing Enterobacteriaceae are currently of special concern (Seiffert et al., 2013). With regard to foods of animal origin, in particular healthy chickens as carriers and contaminated poultry products are

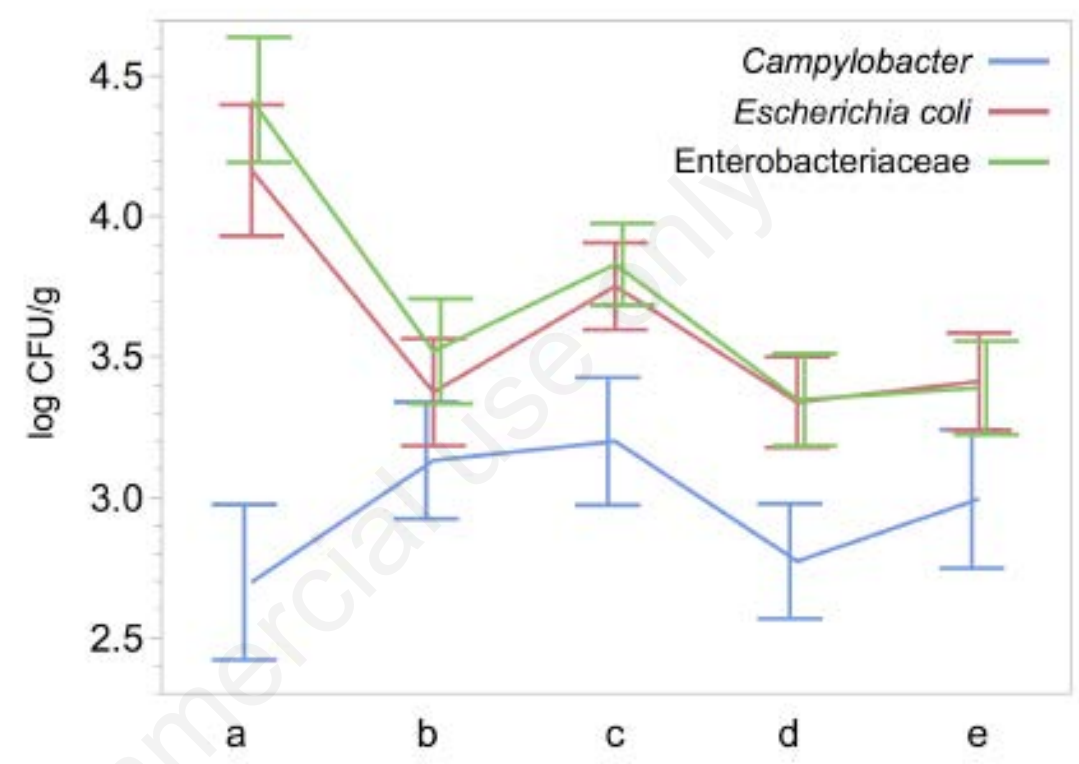

Figure 1. Mean Campylobacter, Escherichia coli, and Enterobacteriaceae counts from broiler carcasses with results $\geq 2.3 \log$ CFU/g: (a) after scalding, (b) after plucking, (c) after evisceration, (d) after washing, and (e) in the chiller (error bars represent $95 \%$ confidence intervals).

Table 2. Planned process hygiene criterion for Campylobacter on broiler carcasses after chilling in the European Union (amendment to Reg. [EC] No. 2073/2005).

\begin{tabular}{|c|c|c|c|c|c|}
\hline \multirow{2}{*}{\multicolumn{2}{|c|}{ Microorganisms }} & \multicolumn{2}{|c|}{ Sampling plan ${ }^{\mathrm{a}}$} & \multirow[t]{2}{*}{ Limits } & \multirow[t]{2}{*}{ Action in case of unsatisfactory results } \\
\hline & & & c & & \\
\hline $\begin{array}{l}\text { Carcasses of broilers } \\
\text { (after chilling) }\end{array}$ & Campylobacter & 50 & $20^{c}$ & $1000 \mathrm{CFU} / \mathrm{g}$ & $\begin{array}{l}\text { Improvements in slaughter hygiene, review of process } \\
\text { controls, origin of animals and of the biosecurity } \\
\text { measures in the farms of origin }\end{array}$ \\
\hline
\end{tabular}

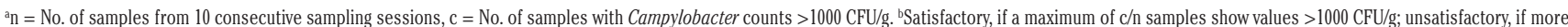
than $\mathrm{c} / \mathrm{n}$ samples show values $>1000 \mathrm{CFU} / \mathrm{g}$. 'From 1.1.2020: $\mathrm{c}=15$, from 1.1.2025: $\mathrm{c}=10$.

Table 3. Campylobacter, Escherichia coli, and Enterobacteriaceae results from scalding water samples $(\mathbf{n}=30)$.

\begin{tabular}{|c|c|c|c|c|c|c|c|c|c|}
\hline \multirow[t]{2}{*}{ Scalding tanka } & \multicolumn{3}{|c|}{ Campylobacter ${ }^{b}$} & \multicolumn{3}{|c|}{ E. coli } & \multicolumn{3}{|c|}{ Enterobacteriaceae } \\
\hline & n pos & $\chi$ & SD & n pos & $\chi$ & SD & n pos & $\chi$ & SD \\
\hline No. $1(n=15)$ & 7 & 2.46 & 0.94 & 15 & 4.11 & 0.69 & 15 & 4.02 & 0.47 \\
\hline No. $2(n=15)$ & 10 & 1.47 & 0.57 & 15 & 3.07 & 0.58 & 15 & 3.18 & 0.52 \\
\hline
\end{tabular}

aTank 1: on average $52.4^{\circ} \mathrm{C}, 120 \mathrm{~s}$, tank 2 : on average $52.5^{\circ} \mathrm{C}, 75 \mathrm{~s}$. ${ }^{\mathrm{b}}$ pos, No. of samples with results $\geq$ detection limit $(1.0 \log \mathrm{CFU} / \mathrm{mL}) ; \chi$ and SD, mean log CFU/mL and standard deviation of results $\geq$ detection limit. 
currently in the focus (Abgottspon et al., 2014; Geser et al., 2012). A high prevalence of $63 \%$ (flock level) was recently reported by examining chicken fecal samples collected at slaughter with an enrichment step (Geser et al., 2012). In the present study, ESBL-producing Enterobacteriaceae (CTX1 producing Escherichia coli and CTX-1 producing Escherichia fergusonii) were found quantitatively on only eight $(1.8 \%)$ broiler carcasses (seven from one sampling day and six from the same flock) and counts ranged from 2.3 to $3.9 \log \mathrm{CFU} / \mathrm{g}$. None of the final chilled carcasses tested positive. In contrast, Pacholewicz et al. (2015a) could recently enumerate ESBL-producing $E$. coli in $82 \%$ of 620 samples collected trough processing in two broiler slaughterhouses in Germany and the Netherlands.

\section{Scalding water}

In the examined poultry abattoir, a twosegment scalding system was used. Such systems are intended to expose the carcasses to less and less contaminated scalding water (Cason et al., 2000; Hinton et al., 2004). In accordance, Campylobacter, E. coli, and Enterobacteriaceae counts were lower $(\mathrm{P}<0.05)$ in the second scalding tank than in the first scalding tank. Differences of mean Campylobacter, E. coli, and Enterobacteriaceae counts thereby accounted for 1.0, 1.0, and $0.8 \log$ $\mathrm{CFU} / \mathrm{mL}$, respectively (Table 3 ). To assess the effect of scalding and the respective parameters (in particular exposition temperature and time), further investigations including carcasses before and after scalding are required. Furthermore, one scalding water sample was positive for Salmonella spp. and one for ESBL-producing Enterobacteriaceae. The Salmonella isolate was identified as Salmonella enterica subsp. enterica 4,12:i:-

\section{Conclusions}

A quantitative microbiological process analysis of broiler carcasses was performed at selected stages (scalding, plucking, evisceration, washing, chilling) in a large-scale poultry abattoir. Campylobacter spp. were found at the different stages on $11 \%$ (after scalding) to $42 \%$ (after plucking) of the carcasses. With regard to Campylobacter counts on carcasses, plucking tended to slightly increase the results (on average by $0.4 \log \mathrm{CFU} / \mathrm{g}$ ). Commonly minor changes occurred at the following stages and mean counts from plucked and chilled carcasses were similar (about $3.0 \log \mathrm{CFU} / \mathrm{g}$ ). Although not directly comparable, Campylobacter results of chilled carcasses are likely to comply with the newly defined EU requirements (process hygiene criterion for Campylobacter). E. coli and Enterobacteriaceae were found in remarkable frequencies and counts in the poultry slaughter process. With regard to E. coli and Enterobacteriaceae counts on carcasses, plucking clearly reduced the results (on average almost by one order of magnitude). Some process stage-specific changes were evident in the following, but mean $E$. coli and Enterobacteriaceae counts from plucked and chilled carcasses were similar (about $3.4 \log \mathrm{CFU} / \mathrm{g}$ ). On the other hand, Salmonella spp. and ESBL-producing Enterobacteriaceae were not or only rarely detected on the broiler carcasses. Such abattoir-specific microbiological data from carcasses form the basis for assessment of slaughter process performance, are of central importance for the implementation of HACCP-based systems, and allow if necessary (e.g. non-compliance with process hygiene criteria) to take targeted measures at selected slaughter process stages.

\section{References}

Abgottspon H, Stephan R, Bagutti C, Brodmann P, Hächler H, Zurfluh K, 2014. Characteristics of extended-spectrum cephalosporin resistant Escherichia coli isolated from Swiss and imported poultry meat. J Food Prot 77:112-5.

Berghaus RD, Thayer SG, Law BF, Mild RM, Hofacre CL, Singer RS, 2013. Enumeration of Salmonella and Campylobacter spp. in environmental farm samples and processing plant carcass rinses from commercial broiler chicken flocks. Appl Environ Microbiol 79:4106-14.

Berrang ME, Dickens JA, 2000. Presence and level of Campylobacter spp. on broiler carcasses throughout the processing plant. J Appl Poult Res 9:43-7.

Boysen L, Rosenquist H, Larsson JT, Nielsen EM, Sørensen G, Nordentoft S, Hald T, 2014. Source attribution of human campylobacteriosis in Denmark. Epidemiol Infect 142:1599-608.

Brown MH, Gill CO, Hollingsworth J, Nickelson II R, Seward S, Sheridan JJ, Stevenson T, Sumner JL, Theno DM, Usborne WR, Zink D, 2000. The role of microbiological testing in systems for assuring the safety of beef. Int J Food Microbiol 62:7-16.

Cason JA, Hinton Jr A, Ingram KD, 2000. Coliform, Escherichia coli, and salmonellae concentrations in a multiple-tank, counterflow poultry scalder. J Food Prot
63:1184-8

Comin D, Valero A, Manfreda G, GarcíaGimeno RM, Paiusco A, De Medici D, Terza P, Ferrarini S, De Cesare A, 2014. Microbiological criteria for Campylobacter in broiler carcasses in Italy: a possible approach to derive them. Int J Food Microbiol 184:64-8.

Duffy LL, Blackall PJ, Cobbold RN, Fegan N, 2014. Quantitative effects of in-line operations on Campylobacter and Escherichia coli through two Australian broiler processing plants. Int J Food Microbiol 188:128-34.

EC, 2005. Regulation of the European Commission (EC) No. 2073/2005 of 15 November 2005 on microbiological criteria for foodstuffs. In: Official Journal, L338/1-26.

EFSA, 2010a. Scientific opinion on quantification of the risk posed by broiler meat to human campylobacteriosis in the EU. EFSA J 8:1437.

EFSA, 2010b. Analysis of the baseline survey on the prevalence of Campylobacter in broiler batches and of Campylobacter and Salmonella on broiler carcasses, in the EU, 2008; part B: analysis of factors associated with Campylobacter colonization of broiler batches and with Campylobacter contamination of broiler carcasses; and investigation of the culture method diagnostic characteristics used to analyze broiler carcass samples. EFSA J 8:1522.

EFSA, 2011. Scientific opinion on Campylobacter in broiler meat production: control options and performance objectives and/or targets at different stages of the food chain. EFSA J 9:2105

EFSA/ECDC, 2016. The European Union summary report on trends and sources of zoonoses, zoonotic agents and foodborne outbreaks in 2012. EFSA J 14:4634.

Geser N, Stephan R, Hächler H, 2012. Occurrence and characteristics of extended-spectrum $\beta$-lactamase (ESBL) producing Enterobacteriaceae in food producing animals, minced meat and raw milk. BMC Vet Res 8:21.

Guerin MT, Sir C, Sargeant JM, Waddell L, O'Connor AM, Wills RW, Bailey RH, Byrd JA, 2010. The change in prevalence of Campylobacter on chicken carcasses during processing. Poultry Sci 89:1070-84.

Habib I, Berkvens D, De Zutter L, Dierick K, Van Huffel X, Speybroeck N, Geeraerd AH, Uyttendaele M, 2012. Campylobacter contamination in broiler carcasses and correlation with slaugh- 
terhouses operational hygiene inspection. Food Microbiol 29:105-12.

Hinton Jr, A, Cason JA, Hume ME, Ingram KD, 2004. Spread of Campylobacter spp. during poultry processing in different seasons. Int J Poultry Sci 3:432-7.

Huang J, Zang X, Zhai W, Guan C, Lei T, Jiao X, 2017. Quantitative analysis of Campylobacter spp. contamination in chicken slaughtering lines by "label tracking method". Food Control 80:6773.

James C, Vincent C, de Andrade Lima TI, James SJ, 2006. The primary chilling of poultry carcasses. Int J Refrig 29:84762.

Lee J, Castle M, Duncan G, Hathaway S, van der Logt $\mathrm{P}$, Wagener S, LassoCruz A, Gichia M, Tebwe T, Silva U, 2015. Example of a microbiological criterion (MC) for verifying the performance of a food safety control system: Campylobacter Performance Target at end of processing of broiler chickens. Food Control 58:23-8.

Loretz M, Stephan R, Zweifel C, 2010. Antimicrobial activity of decontamination treatments for poultry carcasses. Food Control 21:791-804.
Milios KZ, Drosinos EH, Zoiopoulos PE, 2014. Food safety management system validation and verification in meat industry: carcass sampling methods for microbiological hygiene criteria. Food Control 43:74-81.

Nauta M, Hill A, Rosenquist H, Brynestad S, Fetsch A, van der Logt P, Fazil, A, Christensen B, Katsma E, Borck B, Havelaar A, 2009. A comparison of risk assessments on Campylobacter in broiler meat. Int J Food Microbiol 129:10723.

Nauta MJ, Sanaa M, Havelaar AH, 2012. Risk based microbiological criteria for Campylobacter in broiler meat in the European Union. Int J Food Microbiol 158:209-17.

Pacholewicz E, Liakopoulos A, Swart A, Gortemaker B, Dierikx C, Havelaar A, Schmitt H, 2015a. Reduction of extended-spectrum- $\beta$-lactamase- and AmpC$\beta$-lactamase-producing Escherichia coli through processing in two broiler chicken slaughterhouses. Int $\mathrm{J}$ Food Microbiol 215:57-63.

Pacholewicz E, Swart A, Schipper M, Gortemaker BG, Wagenaar JA, Havelaar AH, Lipman LJ, 2015b. A comparison of fluctuations of Campylobacter and Escherichia coli concentrations on broiler chicken carcasses during processing in two slaughterhouses. Int J Food Microbiol 205: 119-27.

Rosenquist H, Sommer HM, Nielsen NL, Christensen BB, 2006. The effect of slaughter operations on the contamination of chicken carcasses with thermotolerant Campylobacter. Int J Food Microbiol 108:226-32.

Seiffert SN, Hilty M, Perreten V, Endimiani A, 2013. Extended-spectrum cephalosporin-resistant Gram-negative organisms in livestock: an emerging problem for human health? Drug Resist Updat 16:22-45.

Seliwiorstow T, Baré J, Van Damme I, Uyttendaele M, De Zutter L, 2015. Campylobacter carcass contamination throughout the slaughter process of Campylobacter-positive broiler batches. Int J Food Microbiol 194:25-31.

Zweifel C, Capek M, Stephan R, 2014. Microbiological contamination of cattle carcasses at different stages of slaughter in two abattoirs. Meat Sci 98:198-202 